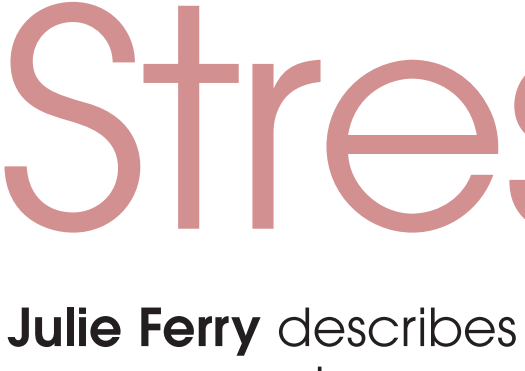 \\ seven ways to combat stress.}

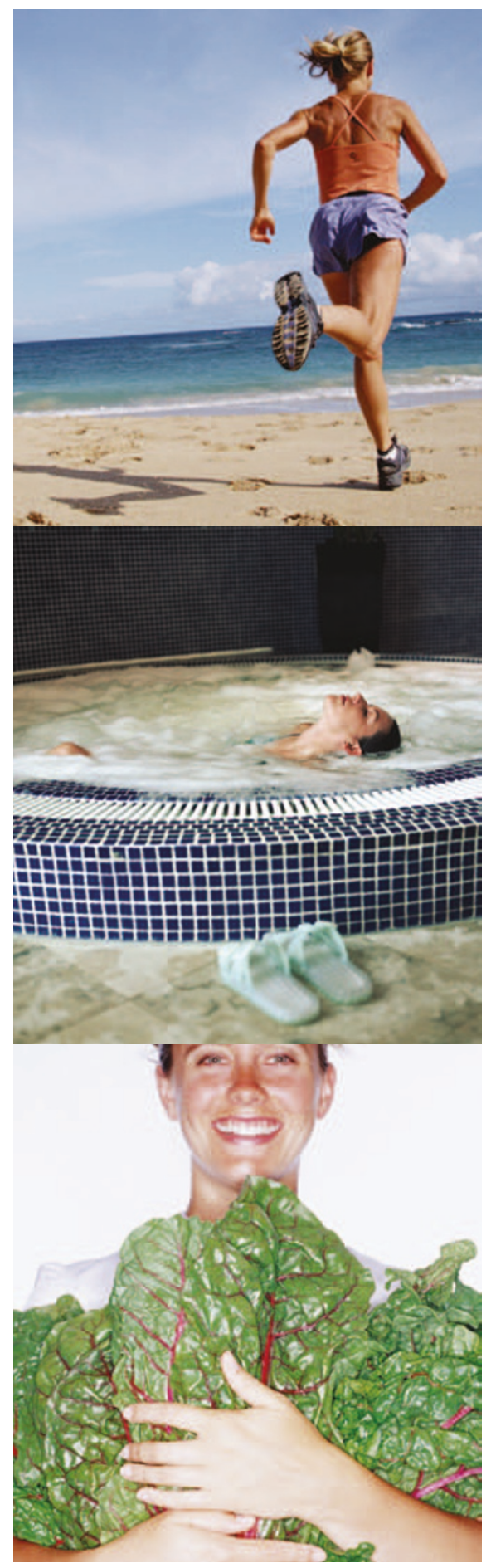

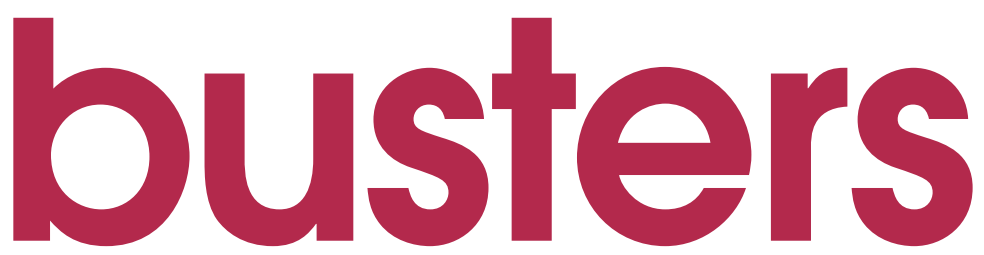

time to this each week, you will soon start to feel the benefits.

\section{Eat well}

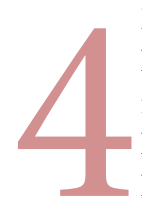

Eating the right foods can also 21 st century, there are some simple steps you can take which can help you reduce the amount of stress that you are under and its effects. The most important thing when trying to manage stress is to pay attention to the little things that you can change in your life. Different techniques work for different people, but if you can manage to implement a few of the tips below, you will be well on your way to making a real difference.

\section{Be organised}

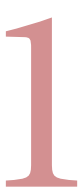

Try and get to work early so that you have time to consider the day ahead. Time management is key to reducing stress, so plan your day and prioritise your work. Of course, not everything can be planned and there will be things that come up and steal time away from other tasks, so make sure you build in extra 'free' time that will help you to catch up. Knowing that you have this time will help you to feel calmer when the unexpected comes up.

\section{Exercise}

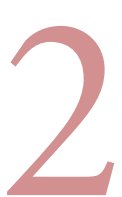

Taking regular exercise is one of the best ways to manage stress. Whether it is a walk at lunchtime or a kickboxing session at the gym, the more time that you can spend on physical activity the better.

\section{Relaxation}

It is important that everybody takes time out to relax. However, this can be one of the hardest techniques to learn if you constantly have other things on your mind. First, try listening to some soothing music, whilst working if necessary, to help you to stay calm. Then, build relaxation time into your life and use it to go for a massage, have a long soak in a bath or practise yoga. Even if you only devote a small amount of help to reduce stress. By choosing foods that release the calming - hormone serotonin and that are high in Vitamin C, you can help give your body a head start on beating the effects of stress. Fresh fruit, walnuts, dates, sesame seeds, sweet potatoes, oily fish and broccoli are all good examples of stressbusting foods. Drinking water to ensure you stay hydrated also helps to keep you alert.

\section{Sleep}

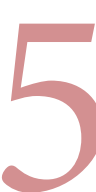

Make sure that you get enough good quality sleep every night. If you are tired, the little things tend to affect you more, making you feel anxious and unable to cope. Feeling rested helps you to take on the challenges of the day ahead.

\section{Saying no}

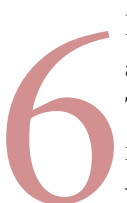

Learn how to say no when people are asking too much of you. Taking on extra work will only increase the pressure and make you feel even more tense. If you feel that you can't manage it, say so and don't feel bad about it, everybody has a limit.

\section{Talking about it}

One of the best ways to alleviate stress is to talk to somebody else about it. If your workload is the problem, talk to your boss about ways to tackle it. Maybe you could build time into your day to catch up on paperwork or work more closely with colleagues so that you all share the burden. Otherwise, talk to your friends or family as a way of getting things off your chest. Having a ten-minute 'work chat' at the end of the day can help to offload your stress and leave you feeling relaxed enough to enjoy your evenings and weekends. 

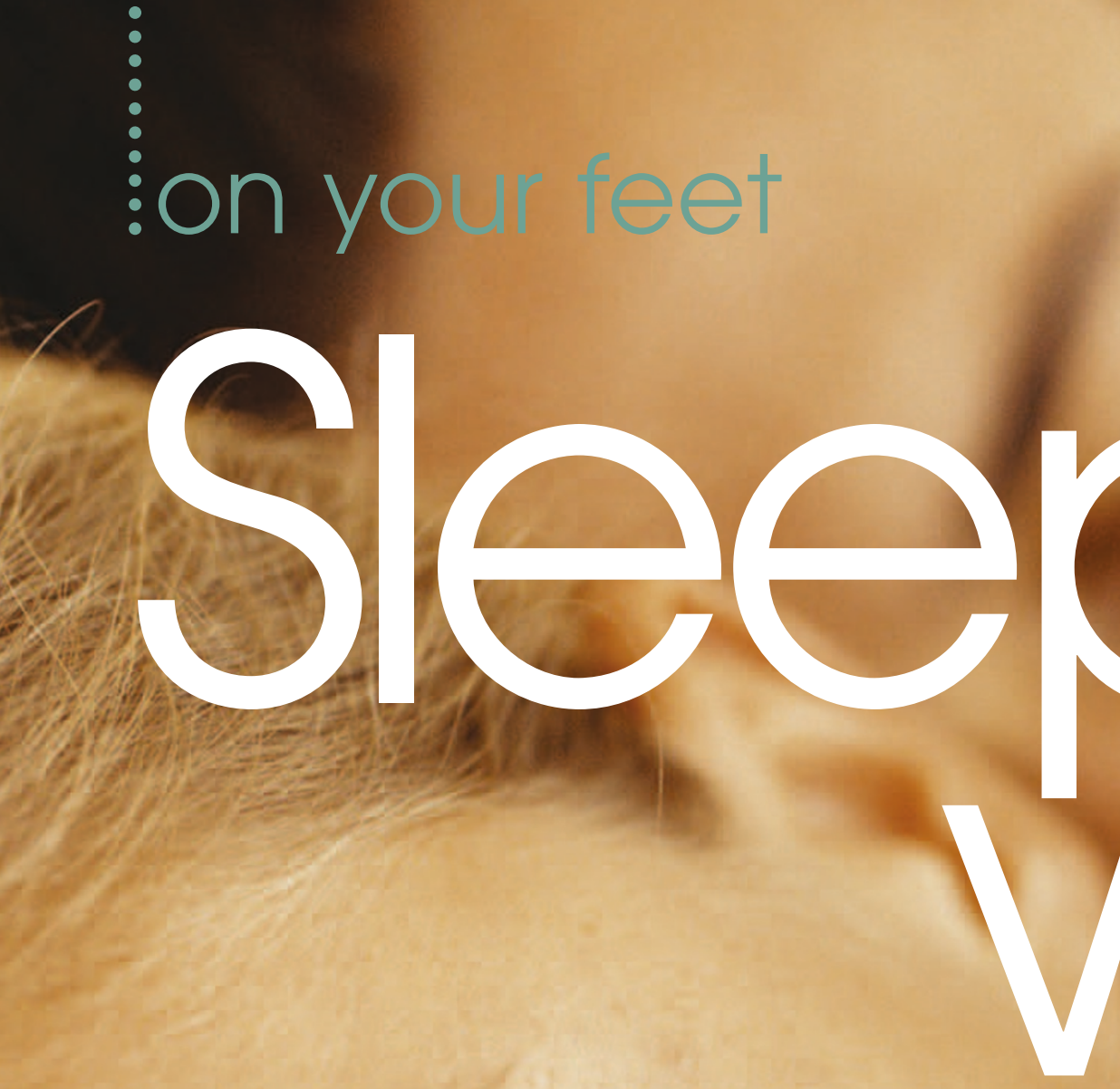

Life becomes so much mor difficult when you can't get to sleep, writes Kate Craig.

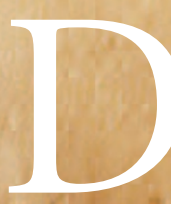

ifficulty sleeping is something that affects most people at some time in their lives. For the fortunate few, it's only when a big decision needs to be made or an important event is imminent. But for many, the inability to sleep is an ongoing problem.

Insomnia is a perception of inadequate For poor-quality sleep as a result of difficul-

ty getting to sleep, difficulty staying asleep or waking up too early in the morning. Not only is it a very tiring condition... it can have a real effect on your quality of life.

The following tips may help you establish a healthy sleep routine:

1. Sleep as much as you need to feel refreshed, but no more.

2. Try to get up at about the same time every morning to help establish a routine.

3. Ensure the bedroom is a quiet, dark, comfortable environment.

4. Only go to bed when you feel sleepy. If you are not tired try reading or doing something else that helps you relax until you feel tired.

5. A hot drink or a light snack before bed may help you sleep.

6. Avoid napping - it can stop you feeling sleepy at bedtime.

7. Try to avoid caffeine, alcohol and smoking - these can all lead to disturbed sleep.

8. Try not to focus on the problems of the

\section{day or what you have planned for} tomorrow. Write yourself a to-do list and then try and put the thoughts out of your mind.

9. Avoid watching the clock. Set your alarm and then place the clock out of sight.

10. Don't panic. If you still can't get to sleep go into another room and do something relaxing.

Insomnia may last for varying periods. It may be transient (lasting a short time), intermittent (occurring on and off) or chronic (lasting more than a month and occurring on most nights).

If you feel you are falling into the intermittent of chronic categories, it may well be worth talking to your doctor.

One thing to remember when you're tossing and turning, is that you are certainly not alone. Difficulty sleeping is a surprisingly common phenomenon. According to a survey by the National Sleep Foundation, ${ }^{1}$ nearly two-thirds of adults experienced problems sleeping a few nights a week during the previous year.

Perhaps the best strategy of all is to stop thinking about sleeping. Add a few drops of lavender to your bath water, fetch yourself a cup of tea and curl up with your favourite book... it's a good excuse for pampering yourself, if nothing else!

1 National Sleep Foundation, USA. Sleep Census 2000 Poll, 2000. 

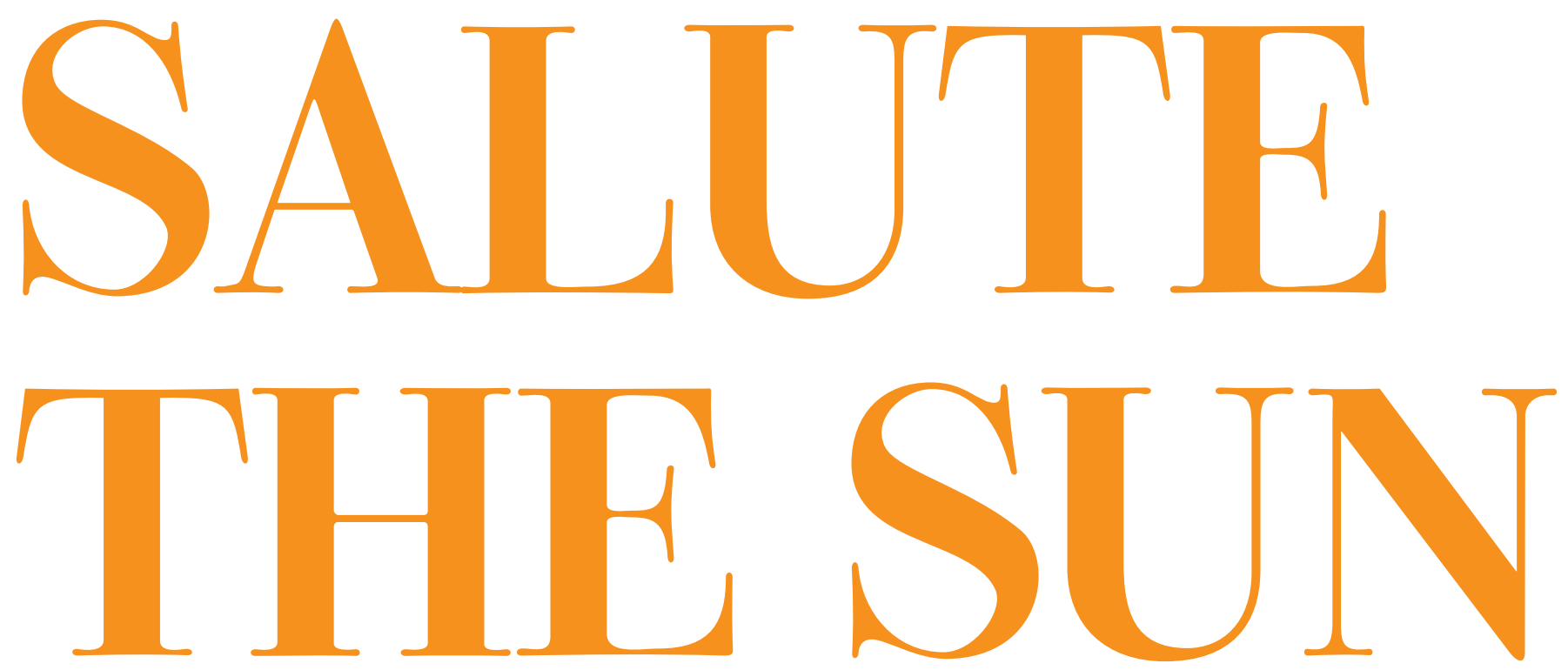

\section{There is a gentler way to stay fit and healthy, build your flexibility and reduce your stress... Kate Maynard says ommmmmm.}

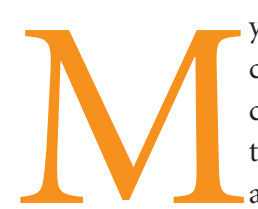

$\mathrm{y}$ first experience of a yoga class involved a lot of muscle shuddering, the realisation that my wrists were about as strong as two brittle sticks, and some hilarity at being surrounded by women of all ages making moaning noises in time with the teacher. I was also called upon to reassure my mother - who came along too - who steadfastly refused to tip her head over backwards for fear of dizziness.

Luckily my initial doubts as to whether yoga was for me soon disappeared as I became familiar with the breathing exercises and sequences of movements, and felt increasingly comfortable in the various postures the teacher gently talks you through. I definitely feel stronger and more flexible as a result of doing yoga, and have noticed that I no longer have back twinges as a result of sitting at a desk all day.

Yoga has probably never been more popular than it is today; you don't have to go far in the UK to find a class, a fanatic who practises at home, or even a yoga weekend retreat. There is so much choice in types of yoga and the teachers running the classes that if you don't like one, it's worth trying another. Sivananda yoga classes and varieties inspired by it are particularly popular, focusing on breathing exercises and relaxation combined with a series of poses including the 'sun salutation', leg lifts, shoulder stands, bending, balancing and other stretches.

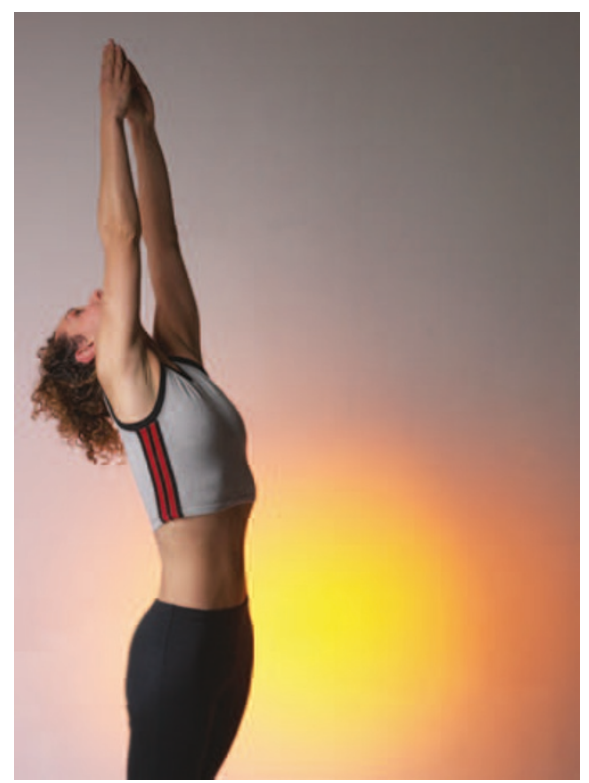

Yoga is far different from a lot of sports and forms of exercise in that it's not competitive and the idea is not to push yourself as far as you can go. Yoga teachers always emphasise that you must work at your own level without straining, and gradually, once you get the hang of synchronising breath and movement, you will notice your stamina and abilities improving.

Alongside an increase in strength and suppleness, there are numerous other benefits to doing yoga. The relaxation aspect will help combat stress, and the exercises also improve circulation, boost energy, improve digestion, massage the internal organs and help you lose weight (in a nicer way than hurtling around the block in trainers or being ordered around by a Nazi-esque gym instructor). Yoga can also be beneficial during pregnancy (but attend a specialised class) and for conditions like arthritis and backache - just make sure your teacher knows about it before the class begins. Forms of yoga like Ashtanga (popularised by celebrities like Madonna and Sting) can involve practising in a heated room - to relax muscles - with a swifter progression from one move to the next, which thus has a more aerobic effect.

Spirituality enthusiasts are also keen on yoga. The very word 'yoga' means 'union' in Sanskrit, a classical Indian language, and implies a fusion between mind, body and spirit. More often than not most yoga classes will end in a series of chants or hums, led by the teacher. Even if you don't exactly feel enlightened, where else do you get the chance to do this?! Attending a yoga class is an ideal way to forget your worries and everyday stresses for an hour or so, and come out feeling calmer and physically stronger. You'll soon be doing 'tree poses' and 'downward facing dogs' in front of the telly!

\section{Useful websites}

www.yogauk.com

www.yoga.co.uk 